\title{
PERANCANGAN JARINGAN KOMPUTER DI CAFE
}

\author{
Mhd habil maulana, indra septy jakarsi \\ Teknik informatika, Fakultas Ilmu Komputer, Universitas Lancang Kuning \\ jl.Yos Sudarso KM.8, Umban Sari, Rumbai,Pekanbaru,Riau 28266 Telp.076152248 \\ abilmaulana95@gmail.com \\ indraseptyjakarsi@gmail.com
}

\begin{abstract}
ABSTRAK
Jaringan komputer adalah sistem yang terdiri dari beberapa komputer yang dirancang untuk dapat berbagi data, informasi, dan sumber daya. Tujuan dari jaringan komputer adalah agar setiap bagian dari jaringan komputer dapat meminta dan menyediakan layanan informasi dan data. Pihak yang meminta atau menerima layanan disebut dengan klien dan siapa yang mengirim atau mengirim layanan disebut dengan server. Di Departemen Pengajaran Fakultas Teknik, Universitas Janabadra mendesain menggunakan topologi jaringan tipe bintang yang telah ada dilakukan agar pengembangan beban jaringan tidak terpusat pada perangkat keras sakelar. Dalam desain jaringan dilakukan mikrotik adalah perangkat jaringan yang berfungsi sebagai gateway serta router. Dalam konfigurasi Alamat IP menggunakan DHCP Server untuk memfasilitasi pemasangan komputer baru di jaringan. Komputer baru tidak perlu dikonfigurasi secara manual, itu akan secara otomatis terhubung ke jaringan
\end{abstract}




\section{PENDAHULUAN}

Kebutuhan akan informasi komunikasi sangat penting seiring dengan kemajuan dan perkembangan teknologi informasi yang semakin canggih dan cepat. Kemajuan teknologi informasi pada saat ini terus berkembang seiring dengan kebutuhan manusia yang mengiginkan kemudahan, kecepatan, dan keakuratan dalam memperoleh informasi. Oleh karena

itu, kemajuan teknologi informasi harus terus diupayakan dan ditingkatkan kualitas dan kuantitasnya. Salah satu kemajuan teknologi informasi di bidang transmisi pada saat ini yang berkembang adalah penggunaan perangkat wireless LAN. Penggunaan internet yang memanfaatkan teknologi wireless LAN atau biasa sering disebut WiFi atau hotspot sangat diminati oleh kalangan masyarakat mulai dari pelajar hingga para pelaku bisnis. Teknologi wireless ini memungkinkan mengakses jaringan internet secara mobile, perangkat yang biasa digunakan biasanya seperti laptop, handphone dengan fasilitas WiFi, PDA, Pocket PC dan lain sebagainya. Namun mereka membutuhkan tempat-tempat tertentu yang menyediakan fasilitas WiFi ini yang akrab disebut dengan hotspot, biasanya tempat-tempat yang menyediakan hotspot seperti cafe, mall, taman, bandara dan tempat umum lainnya. Pada umumnya pengunjung lebih menyukai cafe yang menyediakan fasilitas hotspot, karena mereka dapat mengakses berbagai informasi yang mereka butuhkan. Dengan adanya hal ini di area cafe perlu adanya jaringan hotspot untuk menarik para pelanggannya.

\section{Rumusan Masalah}

Adapun rumusan masalah yang akan penulis bahas adalah mendesain jaringan wireless LAN serta instalasi jaringan wireless LAN dan program managemen hotspot untuk memberikan koneksi internet via Wireless LAN yang diinstal atau dikonfigurasi di PC SERVER.

\section{Batasan Masalah}

Penulis membatasi masalah atas beberapa poin penting, untuk menghindari penyimpanganpenyimpangan dalam tujuan penelitian yaitu :

1. Instalasi dan konfigurasi sistem jaringan Wireless yang dibangun.

2. Adapun yang akan disampaikan berkenaan dengan judul di atas yaitu dasar jaringan komputer, persiapan dan instalasi perangkat Wireless LAN.

3. Instalasi program untuk memonitoring jaringan yaitu dengan Look@LAN.

\section{Tujuan Penelitian}

Tujuan dari judul Desain Jaringan Wireless LAN (hotspot area) pada cafe adalah :

1. Mengenal dan memahami lebih jauh teknologi jaringan komputer, khususnya jaringan wireless/nirkabel (tanpa kabel).

2. Memberi kemudahan khususnya pengunjung cafe dalam mengakses internet.

3. Mengetahui teknik mendesain dan instalasi sebuah jaringan infrastuktur dan implementasinya. 


\section{Manfaat Penelitian}

Manfaat dari penelitian ini adalah memudahkan para pengunjung cafe dalam mengakses internet dan dapat mengetahui desain jaringan wirelles LAN.

\section{LANDASAN TEORI}

\section{Teori}

\section{Wireless LAN}

Wireless adalah suatu koneksi antar satu perangkat dengan perangkat lainnya tanpa menggunakan kabel. Wireless LAN adalah suatu jaringan komputer yang saling terhubung melalui tanpa kabel. Local Area Network dari komputer maupun dari peralatan lainnya dapat dikembangkan lewat sinyal radio atau gelombang cahaya. Teknologi Wireless LAN ada yang menggunakan frekuensi radio untuk mengirim dan menerima data tanpa adanya membutuhan kabel untuk saling menghubungkan. Akibatnya pengguna mempunyai fleksibilitas yang tinggi dan tidak tergantung pada suatu tempat atau lokasi.

Dizaman era globalisasi ini sudah banyak tempat - tempat yang menyediakan koneksi LAN dengan teknologi Wi-fi yang biasa disebut dengan hotspot. Dengan hal ini memungkinan seseorang dengan komputer dengan kartu nirkabel (wireless card) atau personal digital assistant (PDA) untuk terhubung dengan internet dengan menggunakan titik akses (hotspot) terdekat.

Kelebihan dari WLAN :

1. Mobilitas Tinggi

2. Kemudahan dan kecepatan instalasi

3. Menurunkan biaya kepemilikan

4. Fleksibel

5. Scalable

Kekurangan dari WLAN :

1. Delay yang besar

2. Biaya peralatan mahal

3. Adanya masalah propagasi radio seperti terhalang, terpantul, dan banyak sumber interferensi

4. Kapasitas jaringan menghadapi keterbatasan spectrum

5. Keamanan / kerahasiaan data kurang terjamin

6. HotSpot

HotSpot yaitu sebuah area dimana pada area tersebut tersedia koneksi internet wireless yang dapat diakses melalui notebook, PDA maupun perangkat lainnya yang mendukung teknologi 
tersebut, dengan HotSpot kita bisa menikmati akses internet dimanapun kita berada selama di area HotSpot tanpa harus menggunakan kabel, layanan inilah yang nanti diharapkan akan mempercepat akses informasi, kita dapat mengakses langsung internet melalui notebook, PDA dan perangkat lain yang mendukung di area HotSpot, hal inilah yang membuat penulis merasa bahwa sistem HotSpot seperti ini kurang optimal dalam pelayanan dan merugikan server yang ada, karena semua orang dapat mengakses dengan bebas. Oleh sebab itu diperlukan sistem autentifikasi, seperti billing server dan monitoring jaringan HotSpot untuk memaksimalkan layanan tersebut, diharapkan ketika computer notebook mengakses HotSpot akan muncul halaman web yang mengharuskan user mendaftar atau login terlebih dahulu sebelum memakai HotSpot, jadi hanya yang punya account saja yang bisa mennggunakan fasilitas ini.

\section{Switch}

Switch adalah komponen jaringan yang di gunakan untuk menghubungkan beberapa HUB untuk membentuk jaringan yang lebih besar atau menghubungkan komputer-komputer yang mempunyai kebutuhan bandwidth yang besar. Switch memberikan untuk kerja yang jauh lebih baik dari pada HUB dengan harga yang sama atau sedikit lebih mahal. Pada saat sinyal memasuki suatu port di switch, switch melihat alamat tujuan dari frame dan secara internal membangun sebuah koneksi logika dengan port yang terkoneksi ke node tujuan. Port-port lain di switch tidak mengambil bagian di dalam koneksi. Hasilnya adalah setiap port di switch berkorespondensi ke suatu collision tersendiri sehingga kemacatan jaringan terhindari. Jadi, jika suatu Ethernet switch 10-Mbps mempunyai 10 port,maka setiap port secara efektif mendapatkan total bandwidth $10 \mathrm{Mbps}$ sehingga port switch memberikan suatu koneksi yang dedicated ke node tujuan. Switch terbagi dalam 2 tipe utama: switch layer-2 dan layer-3. Switch layer-2 beroperasi pada layer data-link model OSI dan berdsarkan terknologi bridging. Switch tipe ini membangun koneksi logika antar port berdasarkan pada alamat MAC. Switch layer-2 dapat digunakan untuk memecah jaringan yang sedang berjalan ke dalam collision domain yang lebih kecil untuk meningkatkan unjuk kerja. Switch layer-3 beroperasi pada layer-3 dari model OSI dasar teknologi routing. Switch tipe ini membangun koneksi logika antar port berdasarkan alamat jaringan.

\section{Server}

Server adalah sebuah sistem komputer yang menyediakan jenis layanan tertentu dalam sebuah jaringan komputer. Server didukung dengan processor dan RAM yang besar, juga dilengkapi dengan sistem operasi khusus yang disebut sebagai sistem operasi jaringan atau network operating server.

\section{Kabel UTP}

Kabel UTP (Unshielded Twisted Pair) merupakan salah satu jenis kabel yang (komputer, hub, switch, router). Kabel ini berisi empat pasang (pair) kabel yang tiap pairnya dipilin (twisted) atau disusun spiral atau saling berlilitan. Jenis kabel UTP dibagi menjadi 2 yaitu:

\section{Tipe Straight}

Kabel straight merupakan kabel yang memiliki cara pemasangan yang sama antara ujung satu dengan ujung yang lainnya. Kabel straight digunakan untuk menghubungkan 2 device yang berbeda Kabel yang terpenting adalah no 1, 2, 3, dan 6. Kabel 4 dan 5 digunakan 
untuk pengganti kabel yang penting sedangkan no 7 dan 8 digunakan untuk kabel penghantar listrik. Urutan standar kabel straight adalah seperti dibawah ini yaitu sesuai dengan standar TIA/EIA 368B (yang paling banyak dipakai) atau kadang-kadang juga dipakai sesuai standar TIA/EIA 368A sebagai berikut:

Contoh penggunaan kabel straight adalah sebagai berikut :

1) Menghubungkan antara computer dengan switch

2) Menghubungkan computer dengan LAN pada modem cable/DSL

3) Menghubungkan router dengan LAN pada modem cable/DSL

4) Menghubungkan switch ke router

5) Menghubungkan hub ke router

2. Kabel Cross

Kabel cross over merupakan kabel yang memiliki susunan berbeda antara ujung satu dengan ujung dua. Kabel cross over digunakan untuk menghubungkan 2 device yang sama. Gambar dibawah adalah susunan standar kabel cross over.

Contoh penggunaan kabel cross over adalah sebagai berikut :

1) Menghubungkan 2 buah komputer secara langsung

2) Menghubungkan 2 buah switch

3) Menghubungkan 2 buah hub

4) Menghubungkan switch dengan hub

5) Menghubungkan komputer dengan router.

\section{Topologi}

Pada pembuatan desain jarinagan pada ini menggunakan topologi tree. Topologi Tree merupakan kombinasi karakteristik antara topologi star dan topologi bus. Topologi terdiri atas kumpulan topologi star yang dihubungkan dalam satu topologi bus sebagai backbone. Komputer-komputer dihubungkan ke hub, sedangkan hub lain di hubungkan sebagai jalur tulang punggung (backbone) yang mempunyai topologi bus.

Keuntungan menggunakan topologi Tree, yaitu:

1. Kontrol manajemen lebih mudah karena bersifat terpusat dan terbagi dalam tingkatan jenjang.

2. Mudah di kembangkan

3. Didukung oleh hardware dan software dari beberapa perusahaan

Kelemahan menggunakan Topologi Tree yaitu:

1. Jika salah satu node rusak, maka node yang berada di jenjang bagian bawahnya akan rusak. 
2. Dapat terjadi tabrakan file data (collision).

3. Lebih sulit untuk mengkonfigurasi dan memasang kabel daripada topologi lain.

4. Software Monitoring Jaringan (Look@LAN)

Look@LAN merupakan salah satu perangkat lunak (software) yang dapat digunakan untuk melihat komputer (host) pada suatu jaringan komputer lokal (LAN), sehingga kita dapat melihat active services atau fasilitas-fasilitas yang disediakannya. Look@LAN menyediakan fasilitas untuk melihat IP Address, status, distance, operating system yang digunakan, hostname, netBIOS name, netBIOS user, SNMP status dan Trap.

Langkah Kerja

1. Crimping Kabel UTP dengan Konektor RJ 45

2. Kupas kabel luar dari utp, pada saat pengupasan sekitar 1 inchi dari ujun nya agar pada saat melakukan pemasang RJ45 bisa menghasilkan crimping yang bagus dan kuat.

3. Pastikan pada saat mengupas kabel luar tidak mengenai kabel kawat yang di dalamnya 1 pun agar kabel bisa terkoneksi dengan baik, jika terpotong atau tergores pada awal nya memang berjalan dengan baik namun setelah beberapa waktu akan rusak dan tidak terkoneksi lagi.

4. Setelah mengupas kabel luar langkah selanjutnya pisahkan kabel tersebut dan di luruskan pada tiap-tiap kabel agar pada saat di crimping menghasilkan kabel yang berkualitas dn susunlah kabel tersebut seseuai denga tipe yang ingin dibuat.

5. Selanjutnya kita potong semua kabel konduktor dengan cara di rapatkan semua kabel yang tadi sudah di luruskan, usahakan agar potong secara rata dengan sudut 90 derajat sekitar 1/2 inchi dari kabel luar. Jangan potong kabel terlalu pendek agar nanti nya dapat mencengkram kontak konduktor pada RJ45.

6. Masukan kabel konduktor ke RJ45. Pastikan kabel konduktor di pegang secara kuat agar kabel-kabel tersebut tidak mengalami pergeseran susunan kabel (tidak rata) dan masukan kabel dengan urutan awal warna orange dari kiri dan masukan ke RJ45.

7. Masukan kabel ke RJ45 ke crimpping tool dan dorong kabel sampai ke dalam kontak RJ45 pada setiap kabel konduktor lalu tekan alat crimpping sampai berbunyi "klik" pada RJ45.

\section{TAHAPAN}

1. Tahap terakhir adalah pengecekan koneksi kabel dengan mengunakan kabel tester agar semua kabel konduktor bisa di gunakan dengan baik. Jika sudah terkoneksi dengan baik (semua lampu indikator pada kabel tester berkedip/menyala).

2. Instalasi Windows 2003 Server

3. Siapkan CD driver

4. Boot komputer dengan CD windows 2003 server. Atur konfigurasi BIOS agar melakukan BOOT CD/DVD ROM. Masukkan CD/DVD Windows 2003 server.Akan muncul selamat datang di setup windows server 2003. 
5. Tekan tombol Enter untuk Setup Windows Server 2003. Maka akan keluar tampilan Windows Licencing Agreement.

6. Klik tombol F8 jika ingin melanjutkan instalasi Windows Server 2003. Selanjutnya tekan tombol Enter untuk mulai meng-instal Windows Server 2003.

7. Windows Server 2003 akan meminta untuk melakukan format terhadap Hard Disk / Partisi yang akan digunakan pada proses Instalasi Windows Server 2003. Jika anda memilih Partisi C sebagai tempat instalasi windows, arahkan posisi ke partisi C, lalu tekan enter untuk melanjutkannya. Setelah itu pilih file system yang ingin digunakan. Secara Umum terdiri dari dua jenis, yaitu : NTFS dan FAT.

8. Windows Server 2003 akan mem-format Hrd Disk / Partisi Hard Disk yang akan digunakan untuk Instalasi.

9. Setelah proses format Hard Disk / Partisi Hard Disk selesai dilakukan, maka Windows Server 2003 akan mengkopi seluruh file-file instalasi yang dibutuhkan selama proses Instalasi Windows Server 2003.

10. Setelah proses pengkopian seluruh file-file instalasi yang dibutuhkan selama proses Instalasi Windows Server 2003 selesai, maka windows mulai untuk proses instalasinya seperti terlihat pada gambar di bawah ini.

11. Windows Server 2003 akan menampilkan jendela pengaturan Regional and Language Options seperti terlihat pada gambar di bawah.

12. Klik tombol Next, maka akan muncul jendela Personalized Your Software. Masukkan sesuai dengan Nama dan Organisasi yang sesuai dengan lisensi anda.

13. Klik tombol Next, maka akan muncul jendela Your Product Key. Masukkan 25 digit key produk yang anda punya.

14. Setelah itu masukan Licencing Modes klik tombol Next. Pada tahapan ini kita dapat memilih 2 opsi, yaitu Per server dan Per Device (seat). Jika kita berbicara tentang Lisensi Resmi tentu saja hal ini sangat berpengaruh. Jika pilihannya adalah per server, kita memiliki jumlah 1 lisensi untuk berapa pengguna. Jika anda mengisi angka 100 CAL, berarti 1 lisensi yang kita miliki hanya boleh dan bisa diakses oleh 100 user dalam waktu yang bersamaan. CAL atau Client Access License adalah lisensi untuk mendapatkan keabsahan mengakses ke server oleh setiap user atau device yang terhubung ke server. Sebaliknya, jika anda memilih per Device, berarti setiap server yang kita punya memiliki lisensi tersendiri.

15. Masukan Nama Komputer dan Password Administrator dari Windows Server 2003. Kemudian klik tombol Next. Nama Komputer tidak boleh diisi sembarangan, karena akan terkait dengan proses konfigurasi yang lainnya.

16. Masukan Tanggal dan Waktu komputer yang akan di-install Windows Server 2003, kemudian klik tombol Next.

17. Windows Server 2003 akan menampilkan jendela Networking Setting. Jika tidak akan melakukan seting-an standar yang diberikan oleh Windows Server 2003 (Default) saat ini, klik tombol Next.

18. Tunggu beberapa saat, windows akan melakukan proses konfigurasi.

19. Windows Server 2003 telah selesai di Install, langkah berikutnya login ke dalam komputer tersebut dengan menekan tombol keyboard CTRL + Alt + Delete. 
20. Masukan User name dan password administartor, kemudian klik tombol OK.

21. Software Monitoring Jaringan (Look@LAN)

Cara instalasi :

1. Install paket software dengan cara klik ganda ikon lalsetup.exe.

2. Klik tombol Next untuk melanjutkannya.

3. Pilih bahasa yang digunakan untuk instalasi, defaultnya English. Klik Next.

4. Ikuti terus proses instalasinya sampai selesai.

Cara mengoperasikan :

1.Klikikonlook@lan, pada look@lanwizard klik Create New Profile.

2. Klik ikon Create New Profile,klik Manually Specify Scan Range.

3. Isi range IP Address pada Manual Setting range IP,misalkan dari IP Address 192.168.0.1 s.d. 192.168.0.253. Lalu klik Next.

4. Maka akan tampil IP Address atau hostname yang terhubung di jaringan dengan IP range yang sudah kita masukkan.

5. Konfigurasi TP-LINK

6. Buka aplikasi browser atau mozila firefox. Setelah dibuka masukkan IP default di address bar. IP default dari TP link adalah 192.168.1.1, kemudian tekan tombol enter di keyboard.

7. Akan muncul permintaan username dan password. Masukan default username = admin, passwordnya $=$ admin, kemudian tekan OK.

8. Kemudian akan tampil halaman setting TP-link.

9. Untuk memulai melakukan setting, klik pada tombol Quick Setup yang ada pada pojok kiri halaman, kemudian klik pada tombol Next.

\section{LANGKAH BARU}

1. Langkah selanjutnya menentukan WAN connection type ; untuk jenis speedy atau ISP lokal bisa menggunakan Static IP . setelah static IP dipilih, klik pada tombol Next.

2. Masukkan nomor IP, Subnet mask, gateway, dan DNS. Jika sudah diisi semua, klik tombol Next.

3. Selanjutnya menentukan parameter AP mode. Wireless : radio pilih Enable. SSID : tentukan nama. Regional : pilih bahasa (indonesia). chanel : pilih automatic. Mode : pilih yang $54 \mathrm{Mbps}$, jika sudah klik pada tombol Next.

4. Pada tahap ini seluruh setting telah dilakukan, lalu klik pada tombol Finish. 


\section{METODELOGI PENELITIAN}

\section{Kerangka Pemikiran}

Sebagai langkah awal maka perlu adanya identifikasi masalah berkenaan dengan masalah yang dibahas. Kemudian adanya landasan teori yang mengacu kepada hal - hal yang membahas pada peneliian ini. Kerangka pemikiran diharapkan dapat diperoleh gambaran yang lengkap dan menyeluruh tentang tahap- tahap penelitian yang akan dilaksanakan serta keterkaitan antara satu tahap dengan tahap selanjutnya.

1. Identifikasi Masalah

Pada tahap ini penulis merumuskan beberapa permasalahan yang akan dibahas secara rinci dalam kegiatan penelitian.

2. Landasan Teori

Landasan Teori, yaitu tahap mencari informasi tentang teori-teori yang berhubungan dengan penelitian dari sumber-sumber lain seperti buku-buku atau dari sumber lainnya.

3. Pengumpulan Data

Pada tahap ini dilakukan pengumpulan data dengan mengambil teori-teori yang berhubungan dengan penelitian untuk dikembangkan. Penulis juga melakukan pengumpulan data melalui observasi langsung maupun tidak langsung.

4. Perancangan Sistem

Tahap ini dilakukan perancangan unuk melakukan instalasi wireless LAN.

1. Spesifikasi Alat

Spesifikasi : Processor Intel Dual Core (2,6 Ghz) Tray, mainboard Asus PS KPLAM-SE (Astrindo), memory DRD 2 V-gen 2 GB, harddisk 160 GB Sregate/WDC/Maxtor/Samsung/Sata/IDE, Keyboard + Mouse Simbada, cassing Simbada sim-x/V350W + 2 fan CPU, LCD monitor LG Wide Screen 18,5”, DVD-ROM Samsung Lite on.

2. 3 buah PC

Spesifikasi : Processor core 2 duo E7500, 2Gb DDR 3, 500Gb HDD, DVD-RW, NIC, Wifi, Camera, VGA integrated, TV tuner, 17"

WXGA.

3. Wirelless access point TP-LINK

4. Kabel UTP

5. RJ 45

6. Switch HUB

7. Internet Speedy 


\section{DAFTAR PUSTAKA}

1. Herlambang, M. L. (2009). Panduan Lengkap Membangun Sharing Koneksi Internet Di Windows, Mikrotik, Linux dan OpenBSD. Yogyakarta: Andi.

2. Hidayat, N. (2016). Perancangan dan Implementasi Jaringan Hotspot Untuk Akses Internet di SMK Muhammadiyah 2 Sragen. Surakarta: Universitas Muhammadiyah Surakarta.

3. Munandar, A. (2015). Perancangan Dan Implementasi Jaringan Komputer Dengan Studi Kasus di SMK Muhammadiyah 2 Sragen. Surakarta: Universitas Muhammadiyah Surakarta.

4. Rohman, A. N. (2012). Perancangan Dan Pemetaan Jaringan Komputer di STIE AL-ES AF Surakarta. Surakarta: Universitas Muhammadiyah Surakarta.

5. Saliu, A. M. (2013). Internet Authentication and Billing (hotspot) System Using Mikrotik Router Operating System. International Journal of Wireless Communication and Mobile Computing, 51-57.

6. Singh, J., \& Rani, A. (2014). Implementation of College Network Scenario Module by Using CCNA. International Journal of Recent Development in Engineering and Technology, 203207.

7. Sujalwo, Handaga, B., \& Supriyono, H. (2011).Manajemen Jaringan Komputer Dengan Menggunakan Mikrotik Router. KomuniTI, II, 35-36.

8. Zulhikam, A. (2014, Desember 13). Perangkat Keras Internet \& Jenis-Jenis Perangkat Untuk Mengakses Internet. Retrieved from JARINGAN KOMPUTER: http://jaringakomputer.org

9. Aaeza. 2007, Panduan Dasar Setting Jaringan Komputer Lokal LAN (Local Area Network) Menggunakan Windows XP. Akses online pada URL: aaeza.wordpress.com/2007/11/26/p anduan-dasar-setting-jaringankomputer-lokal-lan-local-areanetwork-menggunakanwindowsxp/. Tgl Akses 21/06/2012.

10. Anonymous. 2005. Modul KKPI: Melakukan Koneksi ke Internet dan Bekerja dengan Internet. Direktorat Pendidikan Menengah Kejuruan. Anonymous. 2009. Switch. Akses online pada URL: belajarit.um.ac.id/index.php/hardwar e/12-pengenalan-hardware/71- switch.html. Tanggal Akses 21/06/2012

11. Erdiansyah. 2007. Makalah Jaringan Komputer. Makassar: Elektroteknik Universitas Hasanuddin.

12. Agri-tek Volume 14 Nomor 1 Maret 2013 RANCANG BANGUN JARINGAN 49 Eri. 2009, Pert 5 Komunikasi Data. Akses online pada URL: ericute.files.wordpress.com/2009/04 /pert-51.pdf. Tanggal Akses 15/06/2012.

13. Erwin, Sutomo. 2010. Modul Jaringan Komputer. Surabaya: STIKOM Surabaya Proboyekti, Umi. Pengantar Teknologi Informasi. Prodi Sistem Informasi UKDW. Akses online pada URL:lecturer.ukdw.ac.id/othie/Jaring an Komputer.pdf. Tgl Akses 10/06/2012.

14. Prasimax. 2002, Protokol TCP/IP. Technology Development Center, Depok: PRASIMAX Product Research Division.

15. PP Putra, 2016, "Pengembangan Sistem Keamanan Jaringan Menggunakan Rumusan Snort Rule (Hids) untuk Mendeteksi Serangan Nmap."Satin 2(1). 